\title{
Citation pattern of newsworthy research articles
}

\author{
Manjari Manisha*, G. Mahesh ${ }^{1}$ \\ Academy of Scientific and Innovative Research, CSIR-National Institute of Science, Technology and Development Studies, Dr. K S Krishnan \\ Marg, ${ }^{1}$ CSIR-National Institute of Science Communication and Information Resources, 14-Satsang Vihar Marg, New Delhi, India
}

\begin{abstract}
Popular science magazines cover research articles published in scholarly journals that the magazines perceive as having news value. Despite thousands of research articles being published in research journals, a very few get identified for coverage in popular science magazines, general magazines, and newspapers. Do research articles published in journals that are covered in popular science magazines receive higher citations? We hypothesize that newsworthy articles should receive higher citations as the newsworthiness can be a reflection of higher research value of the articles and also because of the visibility received by the articles owing to its coverage in popular science magazine. To empirically study the citedness, we identified 193 research articles and that were reported in New Scientist magazine in 2001. The characteristics of these articles including the citations received following coverage in New Scientist in 2001 were looked at. It was found that average citations per paper of articles covered in New Scientist was higher than the journal average for the year 2001 for 19 out of the 24 journals identified here.
\end{abstract}

Keywords: Blog, citation, citedness, magazine, media, newsworthy

\section{INTRODUCTION}

Although the coverage of science in the lay press is dismal, major scientific breakthroughs do attract the attention of popular media including print and electronic media. In addition to the general newspapers, science magazines such as New Scientist, Discover, etc., cover recent scientific research published in leading research journals such as Science, Nature, Cell, and many others. The reporting of research articles in the popular science media helps not only the general readers, but also scientists in other areas of research to be aware of the latest research activities in a given area. However, the basis on which the newspapers and general science magazines identify research papers

*Address for correspondence:

E-mail: manjarimanisha@gmail.com

\begin{tabular}{|l|l|}
\hline \multicolumn{2}{|c|}{ Access this article online } \\
\hline Quick Response Code: & \\
\hline & Website: \\
\hline & www.jscires.org \\
\cline { 2 - 3 } & Dol: \\
&
\end{tabular}

published in scholarly journals to be reported upon is not known. However, one can be certain that the popular science magazines select research papers that on its perceived news value. As for coverage of science news in mainstream science media, Petersen ${ }^{[1]}$ states that "articles appearing in mass-circulation science journals such as Nature, Science, New Scientist, Scientific American, and Science News, which provide the source for many stories in the mainstream news media, have been found to draw extensively on popular imagery and metaphors, and to contain gender and heterosexist biases."

In the realm of scientific research, citations have been an indicator to assess the value of a research paper. ${ }^{[2]}$ The time taken for a research paper to gather citations also depend on several factors including the field of research, novelty of the research, ${ }^{[3]}$ type of research, ${ }^{[4]}$ collaborations, ${ }^{[5]}$ etc., It is seen that many papers that are published even in high impact journals never get a citation or may get citations after a several years of actual publication or may get some quick citations that may taper off in a few years. ${ }^{[6,7]}$

It is will be useful to look at the citedness of the research papers that have been covered by news magazines. This study looks at the citations received by those articles that 
have been covered by New Scientist magazine during the year 2001.

\section{REVIEW OF LITERATURE}

In 2010, Moriarty, Jensen and Stryker analyzed the content of 3,656 cancer stories that appeared in media and found that the most frequently cited sources in cancer news articles-research institutions and medical journals receive disproportionately more attention compared to other sources. ${ }^{[8]}$ The study shows that journal articles are an important source of information for the popular media that report science news.

"Does popular coverage of medical research in turn amplify the effects of that research on the scientific community?" Phillips et al. in attempting to answer the question compared the number of references in Science Citation Index to articles in the New England Journal of Medicine (NEJM) that were covered by The New York times with the number of references to similar articles that were not covered by the times. ${ }^{[9]}$ The authors found that articles in NEJM that were covered by the times received a disproportionate number of scientific citations in each of the 10 years after the NEJM articles appeared. The study concluded that coverage of medical research in the popular press amplifies the transmission of medical information from the scientific literature to the research community. Kiernan's study also found similar results. ${ }^{[10]}$

The impact on research articles following its discussion on Technology, Entertainment, and Design (TED) was discussed by Sugimoto and Thelwall. The results of the study suggested that discussions on TED does not impact the academic realm as it does the public sphere. ${ }^{[1]]}$ Likewise, Haustein et al. study on the impact on tweeting of scholarly articles show low correlations between tweets and citations. ${ }^{[12]}$

Shema and Bar-Illan found that articles that have been blogged about receive higher journal citations later than the articles that have been published in the same journal in the same year and haven't received blog citations. Based on the results of their study, the authors suggested that blog citations can be used as an alternative metric source. ${ }^{[13]}$ Fanelli highlighted that citation advantage of research covered by mass media as being poorly studied and reported that compared to research not appearing in newspapers, those featured in British newspapers had around $63 \%$ more citations. ${ }^{[14]}$
As can be noted from the foregoing, the studies on popular coverage of research articles and its impact on citedness are negligible. Even among the studies that have been carried out, the basis of identifying research articles for coverage are varied and approaches that have been adopted to study the relationship are different. This study introduces a new approach by selecting a set of articles that were covered by New Scientist in 2001 .

\section{Objectives of the Study}

- To identify the kinds of research papers selected as news-worthy article

- To study the citation pattern of news-worthy articles.

\section{METHODOLOGY}

To assess how newsworthy articles are cited in subsequent years, we looked through all the issues of New Scientist belonging to the year 2001. Articles in New Scientist that were based on research articles published in journals were studied. Being news items, the brief write-ups do not have references and give limited information about the research paper under discussion. It was found that typically, a news item includes the name of the researcher, the institution, and the journal name. The exact title of the research paper, names of co-authors, volume number, issue number, page number, etc., of the original article are not given in the write-up. For the year 2001, we found that New Scientist published 244 news items about research papers published in different journals. Based on the information contained in these news items, we searched the Web of Science to locate the source items and could locate 193 papers in Web of Science. For the remaining 51 news items, as complete information was not available we could not retrieve the exact records from Web of Science. The complete details of each of the 193 papers along with the citations data 2001-2013 were gathered for analysis using MS-Excel.

\section{Analysis}

It was found that out of the 193 news items appearing in New Scientist in the year 2001, all but five news items were based on research papers published in the same year. Five news items were based on research papers published in journals in 2000. The 193 research papers were published in 85 journals. It was found that 59 papers (31\%) were from the two iconic multi-disciplinary journals Nature and Science. About 27\% (53 papers) belonged to 12 other 
journals from where three or more articles were covered and remaining $42 \%$ (81 papers) were from 71 journals.

Table 1 gives the number of papers, the citation records, and average citations per paper (ACPP) of newsworthy papers. Furthermore, given in the table are the total number of papers published by these journals during the reference year 2001, citations, and ACPP. We have limited the table to 24 journals that had two or more news items in New Scientist.

To assess the ACPP received by papers covered by New Scientist, we also looked at the ACCP of all the articles published in the source journal during the year. We found the ACPP of the articles that were reported in New Scientist is higher than the journal average for 19 out of the 24 journals.

\section{Papers by Subject}

Subject-wise analysis in Table 2 shows that 114 papers out of the 193 papers are from biology $(59 \%)$ followed by seven other disciplines including physics, medicine, geology, engineering, chemistry, environmental science, and psychology constituting the remaining $41 \%$. However, if we were to look at the average citations, two papers in engineering have yielded more citations on an average, followed by chemistry, medicine, and then biology. The papers in geology, psychology, and environmental science have $<100$ citations per paper. It is interesting to see that New Scientist has covered more papers in biological science (59\%) and remaining $41 \%$ papers belong to seven disciplines.

\section{Citations Received}

The break-up of citations received in shown in Table 3. It is seen that one paper has received more than 5000 citations whereas 3 papers have received more than 1000 citations, but $<5000$ citations. In all, 73 papers $(38 \%)$ have received more than 100 citations. Nineteen papers have received $<10$ citations.

\section{CONCLUSION}

Popular and news media such as science magazines play a very important role in the diffusing news about research that has been reported in scholarly journals. Selection of a

Table 1: Citation pattern of newsworthy papers

\begin{tabular}{|c|c|c|c|c|c|c|}
\hline \multirow[t]{2}{*}{ Journals } & \multicolumn{3}{|c|}{ New scientist } & \multicolumn{3}{|c|}{ Source journal } \\
\hline & Papers & Citations & ACPP & Papers & Citations & ACPP \\
\hline Nature & 38 & 7602 & 200.05 & 2828 & 358,472 & 126.75 \\
\hline Science & 21 & 10,085 & 480.24 & 2730 & 322,771 & 118.23 \\
\hline British Medical Journal & 7 & 1198 & 171.14 & 3087 & 44,576 & 14.44 \\
\hline Geophysical Research Letters & 7 & 304 & 43.43 & 1185 & 35,623 & 30.06 \\
\hline Behavioral Ecology and Sociobiology & 6 & 390 & 65.00 & 139 & 5304 & 38.16 \\
\hline Proceedings of the Royal Society B-Biological Sciences & 5 & 342 & 68.40 & 372 & 21,123 & 56.78 \\
\hline Biological Psychiatry & 4 & 223 & 55.75 & 865 & 20,345 & 23.52 \\
\hline Cell & 4 & 2973 & 743.25 & 368 & 88,827 & 241.38 \\
\hline Physical Review Letters & 4 & 1008 & 252.00 & 3164 & 211,444 & 66.83 \\
\hline $\begin{array}{l}\text { Proceedings of the National Academy of Sciences of } \\
\text { the United States of America }\end{array}$ & 4 & 331 & 82.75 & 2811 & 317,549 & 112.97 \\
\hline Applied Animal Behavior Science & 3 & 68 & 22.67 & 123 & 2860 & 23.25 \\
\hline Geology & 3 & 203 & 67.67 & 313 & 16,035 & 51.23 \\
\hline Hormones and Behavior & 3 & 217 & 72.33 & 92 & 3821 & 41.53 \\
\hline Journal of Experimental Biology & 3 & 71 & 23.67 & 410 & 13,025 & 31.77 \\
\hline Behavioral Ecology & 2 & 106 & 53.00 & 113 & 4184 & 37.02 \\
\hline Environmental Science and Technology & 2 & 257 & 128.50 & 929 & 40,265 & 43.34 \\
\hline Genome Research & 2 & 124 & 62.00 & 243 & 20,127 & 82.83 \\
\hline Journal of Agricultural and Food Chemistry & 2 & 108 & 54.00 & 983 & 40,631 & 41.33 \\
\hline Journal of the American Academy of Dermatology & 2 & 39 & 19.50 & 503 & 11,825 & 23.51 \\
\hline Nature Biotechnology & 2 & 312 & 156.00 & 374 & 29,990 & 80.19 \\
\hline Nature Genetics & 2 & 716 & 358.00 & 331 & 59,811 & 180.69 \\
\hline Nature Medicine & 2 & 421 & 210.50 & 522 & 50,840 & 97.39 \\
\hline Nature Neuroscience & 2 & 445 & 222.50 & 282 & 34,561 & 122.56 \\
\hline Neurology & 2 & 229 & 114.50 & 2517 & 56,671 & 22.51 \\
\hline
\end{tabular}

$\mathrm{ACPP}=$ Average citations per paper 
Table 2: Subject areas of newsworthy papers

\begin{tabular}{lccc}
\hline Subject & $\begin{array}{c}\text { Total } \\
\text { paper }\end{array}$ & $\begin{array}{c}\text { Total } \\
\text { citation }\end{array}$ & $\begin{array}{c}\text { Average } \\
\text { citation }\end{array}$ \\
\hline Biology & 114 & 14,350 & 125.87 \\
Physics & 26 & 9828 & 378 \\
General and Internal Medicine & 20 & 2785 & 139.25 \\
Geology & 17 & 1496 & 88 \\
Environmental sciences & 7 & 600 & 85.71 \\
Psychology & 5 & 483 & 96.6 \\
Engineering & 2 & 1120 & 560 \\
Chemistry & 2 & 857 & 428.5 \\
Total & 193 & 31,519 & \\
\hline
\end{tabular}

Table 3: Citations break-up of newsworthy papers

\begin{tabular}{lc}
\hline Number of citation & Number of papers \\
\hline$>5000$ & 1 \\
$1001-5000$ & 3 \\
$501-1000$ & 7 \\
$101-500$ & 62 \\
$51-100$ & 40 \\
$11-50$ & 61 \\
$0-10$ & 19 \\
Total & 193 \\
\hline
\end{tabular}

very few articles from hundreds of articles published every week is based on the perceived news value of the identified articles. It is seen from this study that the majority of the select articles that get covered in popular science magazines do get higher citations. Further, the number of journals from where articles are taken for coverage is very limited with Nature and Science being the most preferred journals.

\section{REFERENCES}

1. Petersen A. The portrayal of research into genetic-based differences of sex and sexual orientation: A study of "popular" science journals, 1980-1997. J Commun Inq 1999;23:163-82.

2. Garfield E. Is citation analysis a legitimate evaluation tool? Scientometrics 1979;1:359-75.

3. Glanzel W, Czerwon HJ. What are highly cited publications? A method applied to German scientific papers, 1980-1989. Res Eval 1992;3:135-41.

4. Johnston DW, Piatti M, Torgler B. Citation success over time: Theory or empirics? Scientometrics 2013;95:1023-9.

5. Lancho-Barrantes BS, Guerrero-Bote VP, Moya-Anegon F. Citation increments between collaborating countries. Scientometrics 2013;94:817-31.

6. Glanzel W, Schubert A. Some facts and figures on highly cited papers in the sciences, 1981-1985. Scientometrics 1992;25:373-80.

7. Crespo A, Herranz N, Li YR, Ruiz-Castillo J. The effect on citation inequality of differences in citation practices at the web of science subject category level. J Assoc Inf Sci 2014;65:1244-56.

8. Moriarty CM, Jensen JD, Stryker JE. Frequently cited sources in cancer news coverage: A content analysis examining the relationship between cancer news content and source citation. Cancer Causes Control 2010;21:41-9.

9. Phillips DP, Kanter EJ, Bednarczyk B, Tastad PL. Importance of the lay press in the transmission of medical knowledge to the scientific community. N Engl J Med 1991;325:1180-3.

10. Kiernan V. Diffusion of news about research. Sci Commun 2003;25:13.

11. Sugimoto $C R$, Thelwal M. Scholars on soap boxes: Science communication and dissemination in TED videos. J AM Soc Inf Sci Technol 2013;64:663-74.

12. Haustein $S$, Peters I, Sugimoto $C R$, Thelwal $M$, Larivière $V$. Tweeting biomedicine: An analysis of tweets and citations in the biomedical literature. J Assoc Inf Sci 2014;65:656-69.

13. Shema H, Bar-Illan J. Do blog citations correlate with a higher number of future citations? Research blogs as a potential source of alternative metrics. J Assoc Inf Sci 2014;65:1018-27.

14. Fanelli D. Any publicity is better than none: Newspaper coverage increases citations, in the UK more than Italy. Scientometrics 2013;95:1167-77.

How to cite this article: Manisha M, Mahesh G. Citation pattern of newsworthy research articles. J Sci Res 2015;4:42-5.

Source of Support: Nil, Conflict of Interest: None declared 